\title{
Impacts of climate change on energy systems in global and regional scenarios
}

\author{
Seleshi G. Yalew $\mathbb{1}^{1,2,3 凶}$, Michelle T. H. van Vliet ${ }^{2,4}$, David E. H. J. Gernaat ${ }^{1,5}$, Fulco Ludwig², \\ Ariel Miara $\mathbb{1}^{6,7}$, Chan Park $\mathbb{D}^{8}$, Edward Byers ${ }^{1}{ }^{9}$, Enrica De Cian ${ }^{10,11}$, Franziska Piontek ${ }^{12}$, Gokul lyer ${ }^{10}{ }^{13}$, \\ loanna Mouratiadou ${ }^{10}$, James Glynn ${ }^{10}{ }^{14}$, Mohamad Hejazi ${ }^{13}$, Olivier Dessens ${ }^{15}$, Pedro Rochedo ${ }^{16}{ }^{16}$, \\ Robert Pietzcker (10) 12, Roberto Schaeffer (iD ${ }^{16}$, Shinichiro Fujimori ${ }^{10}{ }^{17,18}$, Shouro Dasgupta ${ }^{10,11}$, \\ Silvana Mima ${ }^{19}$, Silvia R. Santos da Silva ${ }^{13,20}$, Vaibhav Chaturvedi ${ }^{21}$, Robert Vautard ${ }^{22}$ and \\ Detlef P. van Vuuren ${ }^{10,5}$
}

\begin{abstract}
Although our knowledge of climate change impacts on energy systems has increased substantially over the past few decades, there remains a lack of comprehensive overview of impacts across spatial scales. Here, we analyse results of 220 studies projecting climate impacts on energy systems globally and at the regional scale. Globally, a potential increase in cooling demand and decrease in heating demand can be anticipated, in contrast to slight decreases in hydropower and thermal energy capacity. Impacts at the regional scale are more mixed and relatively uncertain across regions, but strongest impacts are reported for South Asia and Latin America. Our assessment shows that climate impacts on energy systems at regional and global scales are uncertain due partly to the wide range of methods and non-harmonized datasets used. For a comprehensive assessment of climate impacts on energy, we propose a consistent multi-model assessment framework to support regional-to-global-scale energy planning.
\end{abstract}<smiles></smiles>
ssessments of the Intergovernmental Panel on Climate Change (IPCC) and other studies have shown that the energy sector not only contributes to climate change but is also vulnerable to climate change ${ }^{1-3}$. These impacts are related to different aspects of energy systems, including energy supply and demand, but also to cost and transport of energy.

On the supply side, renewable energy sources including bioenergy, and hydro, solar and wind power are impacted by climate change in varying degrees due to changes and variability in precipitation, temperature, wind speed and solar irradiation ${ }^{2,4-7}$. Thermal power plants (for example, fossil fuel, biomass and nuclear) face temperature-related impacts on cooling systems and, less substantial, on turbine efficiency ${ }^{8}$. With changes in climate, impacts on thermal power plant may be exacerbated due to national and regional environmental regulations on cooling water withdrawal, consumption and release into natural water bodies, which may result in power generation curtailments $s^{9,10}$. Climate change and climate extremes can also affect the resilience of energy systems and the reliability of energy supply, via impacts on transmission systems or infrastructure siting $^{3,11-13}$. Furthermore, climate change may impact energy supply potentials (for example, for bioenergy) although impacts on land use and competition with other sectors such as food production ${ }^{14}$.

On the demand side, climate change influences energy demand by affecting the duration and magnitude of diurnal and seasonal heating and cooling requirements ${ }^{15}$. Finally, climate change may impact energy systems indirectly by affecting cross-sectoral competition for resources, such as water for producing hydropower, for cooling thermal power plants and/or for uses such as domestic supply, freshwater ecosystems, irrigation and manufacturing ${ }^{16}$. This could indicate additional energy demand for alternative water sources, such as for desalinization.

Understandably, energy systems can also adapt to climate change impacts. Adaptation mechanisms may include reducing energy demand, reducing water demands for cooling operations through alternative cooling technologies (that is, recirculating versus once-through), increasing energy generation capacity and energy storage $^{17}$. The vulnerability of the energy sector can also be reduced by changes in the mix of electricity generation technologies ${ }^{3}$.

\footnotetext{
${ }^{1}$ Copernicus Institute of Sustainable Development, Utrecht University, Utrecht, the Netherlands. ${ }^{2}$ Water Systems and Global Change Group, Wageningen University, Wageningen, the Netherlands. ${ }^{3}$ Policy Analysis, Department of Multi-Actor Systems, Technical University of Delft, Delft, the Netherlands. ${ }^{4}$ Department of Physical Geography, Utrecht University, Utrecht, the Netherlands. ${ }^{5}$ Netherlands Environmental Assessment Agency-PBL, The Hague, the Netherlands. ${ }^{6}$ Advanced Science Research Center, GC/CUNY, New York City, NY, USA. ${ }^{7}$ National Renewable Energy Laboratory, Golden, CO, USA. ${ }^{8}$ Department of Landscape Architecture, College of Urban Science, University of Seoul, Seoul, Korea. ${ }^{9}$ International Institute for Applied Systems Analysis-IIASA, Laxenburg, Austria. ${ }^{10}$ Fondazione CMCC, Venice, Italy. ${ }^{11}$ Università Ca' Foscari Venezia, Venice, Italy. ${ }^{12}$ Potsdam Institute for Climate Impact Research, Leibniz Association, Potsdam, Germany. ${ }^{13}$ Joint Global Change Research Institute, Pacific Northwest National Laboratory, College Park, MD, USA. ${ }^{14}$ MaREI Centre, Environmental Research Institute, University College Cork, Cork, Ireland. ${ }^{15}$ Institute for Sustainable Resources, University College London, London, UK. ${ }^{16}$ Programa de Planejamento Energético, COPPE, Universidade Federal do Rio de Janeiro, Rio de Janeiro, Brazil. ${ }^{17}$ Center for Social and Environmental Systems Research, National Institute for Environmental Studies, Tsukuba, Japan. ${ }^{18}$ Department of Environmental Engineering, Kyoto University, Kyoto, Japan. ${ }^{19}$ Laboratoire d'économie appliquée de Grenoble, Grenoble, France. ${ }^{20}$ Department of Atmospheric and Oceanic Science, University of Maryland, College Park, MD, USA. ${ }^{21}$ Council on Energy, Environment and Water, New Delhi, India. ${ }^{22}$ Laboratoire des Sciences du Climat et I'Environnement-LSCE, Paris, France.凶e-mail: seleshiget@gmail.com
} 

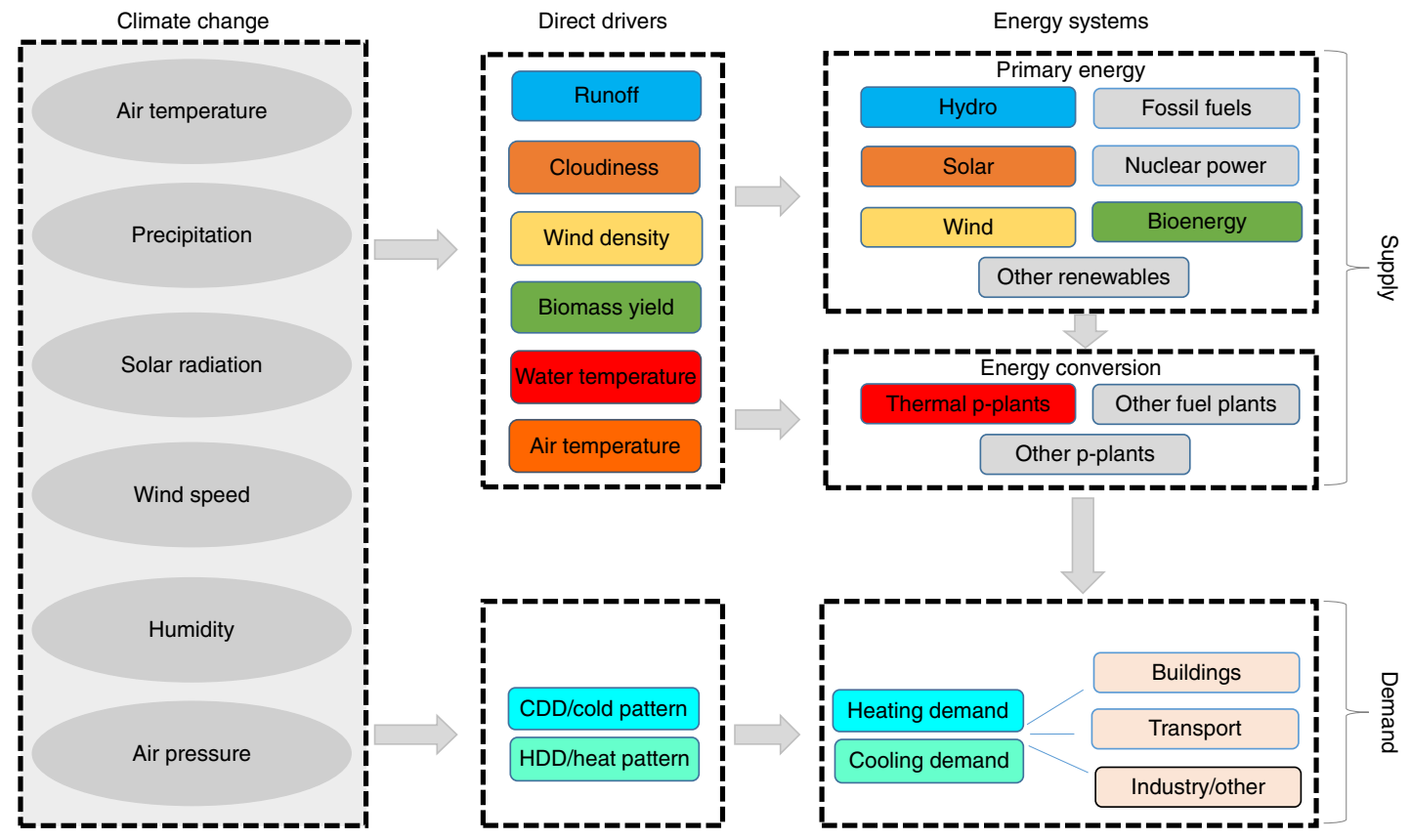

Fig. 1 | Conceptual framework of our assessment of climate change impacts on energy systems, based on past studies. Energy systems include supplies for primary energy from hydropower, solar energy, wind power, bioenergy, other renewables, nuclear power and fossil fuels. It also includes the conversion to secondary energy sources (power plants), electric power grids and transports, as well as energy demand in buildings, transport and industry. Box elements shown in various colours in the figure show association/matching of direct drivers and energy systems. For example, hydropower is driven mainly by runoff, and thermal power plants (thermal p-plants) are mainly driven by water temperature, and hence with respective matching colours. Box element 'Air Temperature' is not matched to a single other element due to its potential impact of energy systems in more than one box. Box elements in grey-coloured boxes are not discussed here (as much less information is found in the literature). CDD, cooling degree days; HDD, heating degree days.

In the last two decades, an increasing number of studies have quantified the potential impacts of projected climate change on the energy sector. However, a recent systematic analysis of the literature is lacking. Given the growing literature on climate change impacts on the energy sector, a synthesis of climate impacts on energy systems using scenario results from the existing literature and exploration of potential assessment frameworks particularly at regional and global scales is necessary.

Here, we review the literature on projected climate change impacts on regional and global energy systems. We synthesize the potential climate change impacts on energy systems at regional and global scales, and we show that climate change impacts vary largely per region and per energy source. Overall, this study identifies regional and global-scale knowledge gaps on climate change impacts on energy systems and provides insight that can guide future research and assessment frameworks.

\section{Current understanding of energy sector vulnerabilities}

Several papers have reviewed the literature on specific segments of energy systems (we use the term 'energy systems' to refer to all components related to the production, conversion, transport and use of energy ${ }^{14}$, see Fig. 1). These include reviews of climate impact on hydropower ${ }^{18}$, solar ${ }^{19}$, wind ${ }^{20}$, bioenergy ${ }^{21}$, thermal power, cooling and heating ${ }^{22}$, costs and electricity markets ${ }^{23-25}$, critical infrastructure $^{26}$ and multi-segment impacts s, $^{2,28}$.

In this study, climate change impacts on energy systems are analysed using results from a total of 220 papers published between the years 2002-2019 (see Supplementary Table 1). Impacts on energy systems are analysed here in terms of impacts on the supply, demand and integrating systems. The supply side concerns renewable energy potentials from solar, wind and bioenergy, as well as thermal power plants in general. The demand side concerns heating and cooling demands. Integrating systems include costs and transport/transmission systems.

Our review shows that the number of publications has strongly increased in the last eight years, from only a few papers per year to more than 30 in 2019, indicating a notable increase in interest on the topic (Fig. 2b). The topic studied most in relation to climate change impacts on energy is hydropower, accounting for about one-third of the reviewed publications (Fig. 2a). The second largest topic discussed in the literature on climate change impacts relates to impacts on energy systems in general. The third largest topic covers papers examining climate impacts on demand for heating and cooling. About one-third of all papers are well cited ( $>25$ times, Fig. 2a).

In the following sections, we summarize the state of knowledge on the impacts of climate change on energy systems on the basis of findings from our analysis.

\section{Impacts on energy systems}

On the supply side, the impacts of climate change on hydropower result from changes in precipitation, evaporation and resulting runoff patterns that affect the variability and volumes of streamflow $^{29,30}$. Most studies investigating climate change impacts on hydropower focus on regional (that is, river basin or country) scales and find differentiated impacts of climate change across regions, with a prevalence of projected decrease in hydropower potential $^{31,32}$ (Fig. 3). Studies of hydropower on a global scale typically show both positive and negative climate change impacts in different regions, leading to a small aggregated decrease in potential $^{33-37}$. With many of these studies, notable seasonal variability and uncertainty in climate change impacts on hydropower generation have been reported on various regions and magnitudes of impacts on individual plants level relative to the regional and global level ${ }^{38-40}$. 

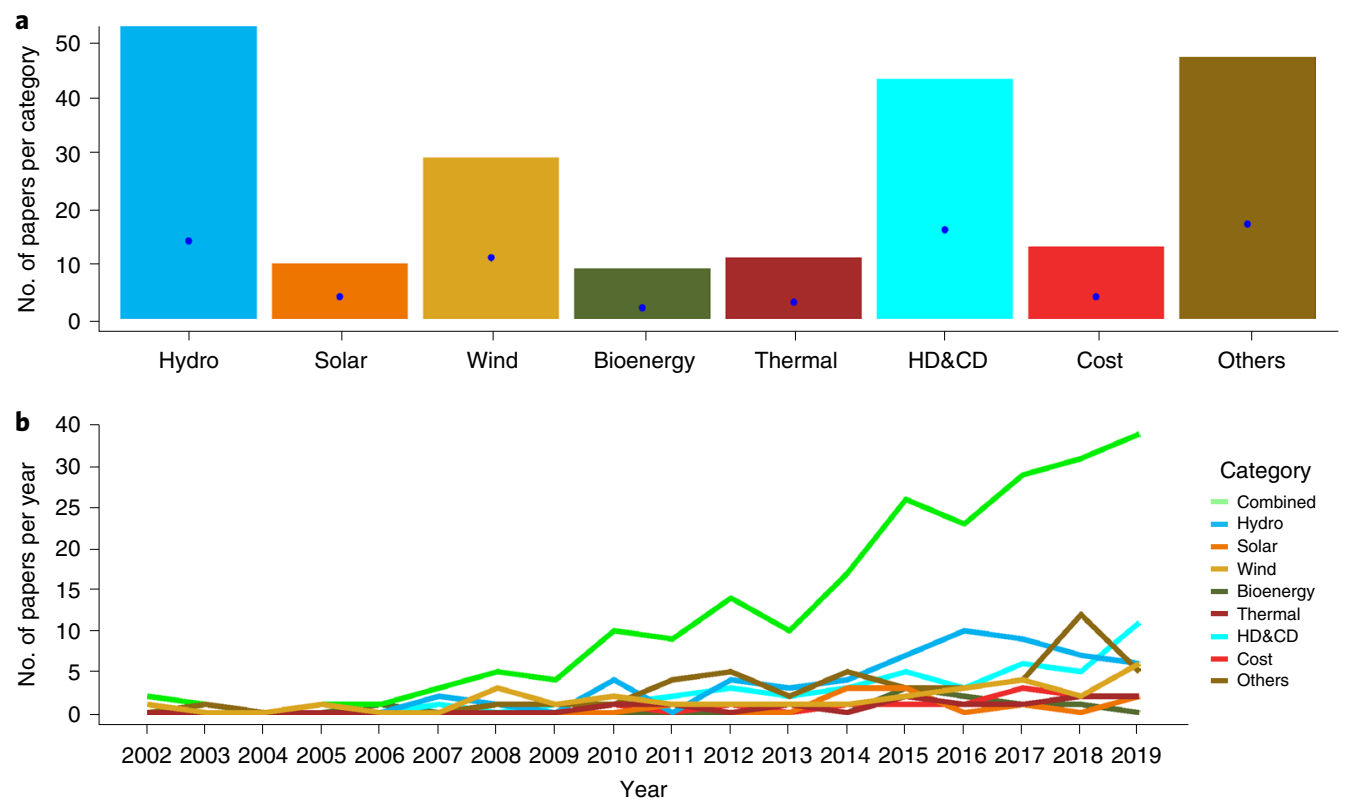

Fig. 2 | Number of papers published from 2002 to 2019 about climate change impacts on renewable energy supply, energy demand and integrating energy systems. a,b, Sorted by energy sources and/or relevant topics (a) and by year (b). 'CD' denotes cooling demand, 'HD' denotes heating demand, 'Others' covers transmission, investments and generic assessments. The blue dot on each bar represents the number of publications with more than 25 citations. The choice of 25 as a threshold was taken somehow arbitrarily and irrespective of year of publication to provide a simplified indication of what proportion of the papers were well cited. However, please note that more recent but potentially high impact papers may have citations fewer than the stated threshold and may have been undervalued in the graph.

Studies typically report unremarkable or small positive effects of climate change on regional solar power potentials as a net result of changes in irradiation and temperature ${ }^{41-43}$, with conflicting changes across simulation ensembles in some cases ${ }^{44}$. The findings of climate impacts on wind power potential are mixed (Fig. 3), with diverging results across regions as well as between studies. For Europe, for instance, both increases and decreases are reported ${ }^{42,45-50}$. More specifically, wind power decreases are reported particularly for southern Europe ${ }^{46-48}$, while slight increases in wind power are projected for central and northern Europe ${ }^{48}$. Some regional studies found a low probability of wind power changes for South Africa ${ }^{41}$, whereas others reported favourable future wind power conditions for parts of the United States and Brazil ${ }^{51-55}$. However, a recent global study showed increasing wind energy potential in the Southern hemisphere in general ${ }^{7}$.

Results of climate change impacts on bioenergy potential are typically mixed ${ }^{56,57}$. A key element refers to the effect of $\mathrm{CO}_{2}$ fertilization (which could lead to an increase in potential), associated with temperature and precipitation impacts (decrease) and competition with other land uses as a result of climate change ${ }^{58,59}$. Thus, the quantification of climate impacts on bioenergy remains complex due to uncertainties associated with regional variation, and future land and water availability ${ }^{21}$.

Climate change is expected to reduce cooling-based thermal power capacity through reduced streamflow, warming ambient and streamflow temperatures (Fig. 3). Global assessments of the vulnerability of the current freshwater-cooled thermoelectric plants project that more than $80 \%$ of plants world-wide will show some reduction in usable capacity9. A number of studies have shown increasingly negative effects of climate change on thermoelectric power plants in Europe and the United States ${ }^{6,60,61}$. However, the effect of reduced available capacity of thermal power plants on the power system, in terms of emissions, cost and reliability, may become less important as we go towards more renewables, and is thus dependent on future capacity expansion and market scenarios ${ }^{62}$. Few studies have explicitly included the impacts on thermal power plants with carbon capture and storage ${ }^{63}$, which are expected to have increased cooling water requirements.

On the demand side, a large body of literature has studied climate change impacts on energy demands for heating and cooling at regional or global scales, with a major focus on the residential sector ${ }^{15,22,64-75}$. Applying either econometric approaches or process-based approaches, these papers generally report decreases in heating demand in cold regions and increases in cooling demand in warm regions ${ }^{15,22,66,67,73,74,7}$. Furthermore, the seasonal impact of climate change on energy demand is anticipated to result in reduced demand for electricity during the cold season and a higher demand during the warm season ${ }^{68,77-80}$. The net effect of global energy use is reportedly small, especially in earlier studies ${ }^{15}$, due to compensation of decreases in heating demand by increases in cooling demand. However, more recent work point at larger net impacts once impacts on non-residential sectors, such as industry and commercial, as well as the amplification effect of air conditioning penetration are considered $^{81}$. The most substantial impact on energy demand, particularly in the built environment, is anticipated to occur in the hot summer and warm winter climates ${ }^{22}$. Increases in cooling demand also depend strongly on socio-economic development such as the affordability of space cooling, energy prices, building stock and adaptation practices ${ }^{7,82,83}$. Furthermore, climate extremes are anticipated to escalate energy demands ${ }^{84-86}$. Extreme weather events, both heatwaves and cold spells, can test system reliability by driving energy demand to its limits, for example, for cooling or heating, respectively ${ }^{13}$. It is indicated that future energy peak demand may increase more than energy consumption ${ }^{86}$. However, energy demand projections involve a number of uncertainties, particularly in relation to user behaviour ${ }^{87-89}$ and large-scale retrofitting projects in the built environment, which can all affect the design and performance of future energy systems ${ }^{90,91}$.

On integrating systems, climate change can affect the future performance, price and availability of existing plants through impacts 
a
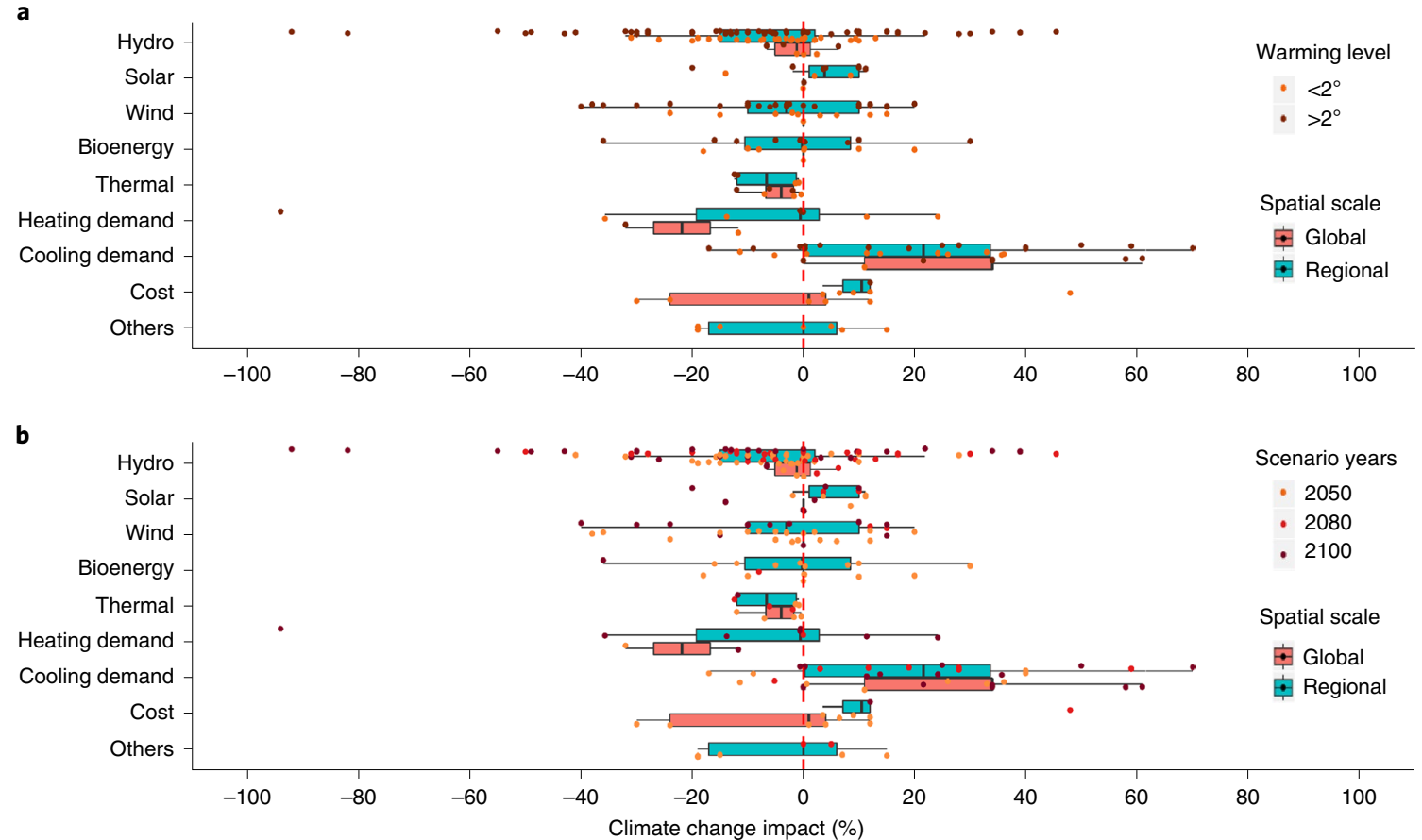

Fig. 3 | Climate change impacts on energy systems. a,b, Impacts per future warming levels (a) and by scenario years/period (b), as reported by studies on global and regional spatial scales. The box plots display a five-number statistical summary of the data set: minimum (end of line, left), first quartile (end of box, left), median (midline in the box), third quartile (right from midline in the box) and maximum (end of line, right). Dots represent individual studies, and boxes represent interquartile ranges. Dots outside the lines are statistical 'outliers'. 'Others' denotes generic assessments and transport/transmission.

on demand and supply ${ }^{92,93}$. At the same time, climate change could also lead to a more synchronized load profile (for example, cooling demand increasing when photovoltaic supply peaks). In the literature, some studies have looked at the impacts on energy systems as a whole in terms of total costs ${ }^{94,95}$. Furthermore, studies ${ }^{35,96}$ have reported that hydropower plants in Latin America, as well as in Europe and the Middle East, are likely to need additional investments to mitigate climate change impacts on electricity infrastructures. There are also reports suggesting that countries such as Bhutan, Canada and Norway will require less power sector investment as a result of increased runoff for hydropower generation, whereas others found about 5\% increased costs in the cost-optimal system design for Europe when climate impacts on hydro, solar and wind power capacity factors are taken into account.

The climate change impacts discussed so far may have notable implications on the reliability of energy systems as a whole. The increasing impacts of extremes on supply and demand will have consequences for system reliability. Climate change affects expenditures such as for adaptation, storage and/or generation of energy. Expenditure on heating and cooling has been indicated to vary regionally: net expenditure will decrease in regions where heating demands currently dominate and will increase in areas where greater demand for space cooling is currently required ${ }^{72,74,81,86}$. The expected change of the frequency and strength of climate extremes as well as changes in variability can affect costs of energy in general (investment or consumption) and associated critical infrastructures in particular ${ }^{27,84,85,97-101}$.

The energy sector is, therefore, potentially highly impacted (alongside industry and transport), with thermal electricity generation bearing most of the risk from heatwaves and droughts, while transmission and renewable technologies are more risk-sensitive to cold waves, wildfires, flooding, heavy snow, ice storms and windstorms. Peak energy demands in summer coinciding with reduced transmission and distribution capacity at higher temperatures are also expected to bring challenges to operation of electricity grids ${ }^{102}$. Cascading effects during extreme events, such as flooding and other environmental hazards (for example, tropical cyclones), may result in power grid and transmission line disruptions ${ }^{13,103}$. This can lead to cross-border effects, as was recently the case when the damages of cyclone Idai to the Mozambique's power grid resulted in blackouts in South Africa (https://www.cf r.org/blog/south-africas-blackouts-demonstrate-need-distributedenergy-resources).

\section{Regional impacts}

Our analysis of results from the reviewed papers shows large regional differences in climate change impacts across almost all energy technologies. While this sometimes reveals real geographic differences in the manifestation of future climate change, in other cases methodological differences between studies may also play a role (see Methods for details).

Changes in hydropower potential are mixed in most regions and mostly depend on the projected climate change patterns across different studies. In general, substantial reduction of potential is projected for Latin America and South Asia, and a smaller reduction for Western Europe, the Middle East and North Africa. Hydropower is the only renewable energy source for which the current literature provides a more complete picture for all global regions, whereas studies on the other renewables have large gaps in regional coverage (Fig. 4). Further details on the number of studies per region and per topic are presented in Supplementary Table 2, and Supplementary Fig. 1 shows regions of the spatial aggregation used here.

The results are mixed for bioenergy, solar and wind power potentials, and often information is still lacking. On the basis of studies on existing plants, thermoelectric potential on a global scale and in Europe shows a reduction in capacity mainly due to rising water temperatures. However, this prospect may change with the potential retirement of less efficient steam plants and the introduction of 


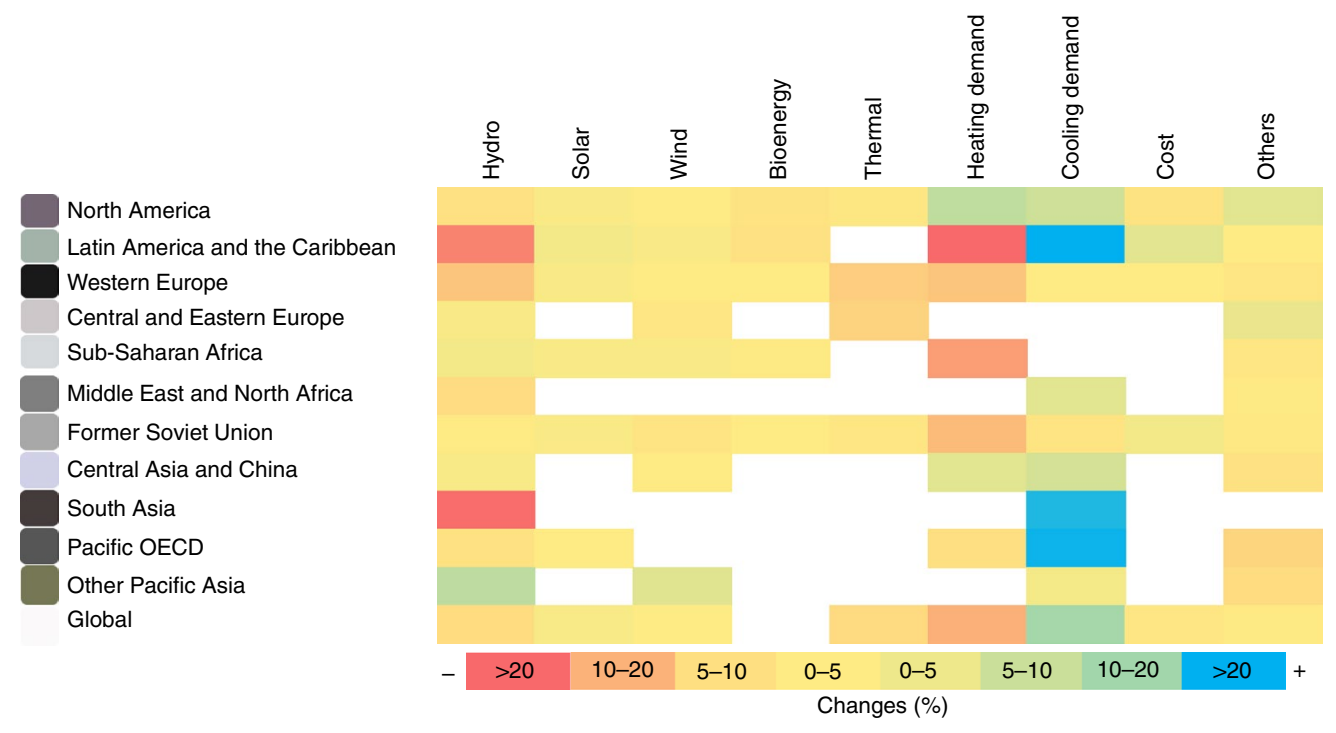

Fig. 4 | Climate change impacts on energy systems averaged across studies, presented per region from results of the reviewed studies. Cells with a red background represent large decreases. Cell colours transitioning from yellow to orange indicate slight decreases. Cells with a blue background represent large increases, and colours transitioning from yellow to blue indicate slight increases. Blank spaces in cells represent 'no studies' in the associated regions and energy systems, indicating that some regions are in clear need of more studies relative to others.

newer, more efficient plants in the future. For heating and cooling demand, the Latin America, South Asia and Pacific Organisation for Economic Co-operation and Development regions stand out for having a clear increase in cooling demand.

Results of climate impacts on costs show mixed results at the global level, but mostly increased costs at the regional level. This counterintuitive result is most likely a result of the limited number of studies. This highlights the need for more comprehensive regional studies, which could better inform global-scale assessments.

Furthermore, large differences exist between the results of individual studies, leading to opposing signals of climate impacts on energy systems that cancel each other out while being aggregated (see Methods). As a result, the degree of uncertainty of the long-term modelling outcomes of climate change impacts on energy has not been well investigated ${ }^{25}$, and thus high uncertainties remain in our understanding, even regarding the available model results.

\section{Key gaps and the way forwards}

This analysis shows that despite the fact that more than 200 papers looked at climate impacts on energy systems: until now, relatively few comprehensive papers have been published on the impacts of climate change on energy systems as a whole. This is in contrast to the number of papers on climate change impacts in other sectors, such as in agriculture and water. The use of diverse methodologies in the energy sector studies also limits the comparability of climate change effects across different studies. We briefly discuss these systematic shortcomings next and recommend possible steps forwards.

The analysis shows that a wide variety of temporal and spatial scales, climate scenarios and warming levels were used in the literature. This makes the comparison and/or synthesis of results from different studies difficult. Moreover, very little inter-method or inter-model comparisons have been done to understand the underlying uncertainties. As studies are typically done using a single energy model and climate change scenario-it means that often for individual technologies and regions different models and scenarios are used, making it difficult to provide a comparable assessment. Furthermore, the role of spatial scale and resolution in climate change impact assessment has hardly been investigated ${ }^{104}$. Proper accounting of climate impacts on energy systems would require a harmonized effort using consistent inputs and methods across all scales and looking into the relevant uncertainties. As such, the energy sector can learn from the systematic model inter-comparison and multi-model assessments on climate impacts on the agriculture and the water sectors ${ }^{105-107}$. Such inter-comparisons allow for exchange of sectoral knowledge, improvement of the quality and consistency of input and output datasets, and critical examinations to reduce epistemic uncertainties that arise from different structural and parametric configurations of the involved models. While model comparison for energy scenarios (from energy models and integrated assessment models) also has a long-standing tradition (for example, in the context of the Energy Modelling Forum, https://emf.stanford. edu/), this is still absent for climate change impacts analysis. Model inter-comparison studies of climate impacts are particularly important in view of the anticipated increase in the adoption of renewable energy, which is highly sensitive to climate change.

Furthermore, energy systems are connected to the consumption and production of food and water, that is, water-energy-food nexus. Climate change impacts can influence this nexus. There are also relevant links to biodiversity (for example, regarding large-scale ramp-up of bioenergy or hydropower), sea-level rise and its effect on coastal energy infrastructure, and the impact of permafrost thawing on oil and gas resource availability. This implies that it important to study the energy sector in an inter-sectoral approach, which will require modelling energy sector impacts at the same spatial scale as other impacts.

The previous paragraphs discussed the importance of assessing climate impacts by comparing energy system models using consistent climate inputs and consistent spatial and temporal scales. This would require a systematic and harmonized assessment based on the results of multiple global climate models, hydrological models, land-use models or regionally downscaled versions of these, in combination with different socio-economic scenario pathways.

One way to do this would be using a global integrated scenario framework similar to the RCP (representative concentration pathway), the SSP (shared socio-economic pathways) framework ${ }^{108}$. The advantage of such a framework in the context of climate change impacts on energy is that it facilitates comparability across 
studies and provides a consistent framework to quantify climate and socio-economic uncertainty ${ }^{109,110}$. The wide use of these scenarios for other issues and regional studies also allows the use of similar assumptions at the regional and/or global scale. Finally, using such a framework enables a systematic evaluation of the socio-economic implications of climate change impacts on energy ${ }^{111}$. Harmonized studies from such frameworks are crucial not only to present a comprehensive overview of the potential impacts of climate change on the supply, demand or integrating energy systems, but also to distinguish between structural (arising from different model structures) and statistical (arising from different assumptions) uncertainties prevalent in current assessment results.

The RCP/SSP matrix can be combined with a set of consistent data from different climate models for climate variables such as solar radiation, temperature, wind speed and other derived products such as biomass yield, land-use suitability and runoff from harmonized input sources. This can be done using data and protocols developed for earlier assessments, in particular the Inter-Sectoral Impact Model Inter-Comparison Project (ISIMIP) ${ }^{112}$. As a potential framework for assessing climate change impact on energy at a macro-regional and global scales, we propose the 'ISIpedia-energy protocol' approach. The protocol, which is currently implemented by several regional and global energy models to simulate energy scenarios (see Supplementary Table 3), harmonizes climatic and socio-economic inputs for energy modelling in line with the specifications of ISIMIP.

In the proposed assessment, a distinction is made on the climate impacts on renewable energy sources, that is, hydropower, solar, wind and bioenergy, and the subsequent impacts for energy systems as a whole (requiring to look at all impacts together). The first step could identify hotspot for various renewable energy supply in terms of aggregated climate change impacts on technical and economic potential at regional as well as global scales. Energy models and integrated assessment models can subsequently be used to assess the implications for future energy system development by using harmonized, consistently bias-corrected climate change input data, shared socio-economic scenarios including consistent land-use input, harmonized $\mathrm{CO}_{2}$ emission scenarios and harmonized temporal and spatial resolutions. The involved models report results in an ensemble manner so that the uncertainty bounds of climate change impact on energy from the different multi-model inter-comparisons results can be represented and visualized clearly. Note that although we focused on impacts of gradual changes in aggregated climate parameters in this proposed framework, multi-model inter-comparison experiments on climate extremes can be important as well, and can create a more comprehensive picture of climate impacts on energy systems. However, such analysis may require different models and model specifications ${ }^{13}$.

The results of the proposed analysis framework could provide important inputs for the Sixth Assessment Report of the IPCC (AR6) and the processes surrounding the implementation of the Paris Agreement. Furthermore, the results can be used for studies relating to the implementation of the Sustainable Development Goals (SDGs), in particular synergies and trade-offs between SDG7 (affordable and clean energy) and SDG13 (climate action). Our review and the ISIMIP-based energy modelling protocol proposed here for inter-comparison of energy systems modelling projections will not replace more detailed and local-scale studies, which continue to push the state-of-the-art analysis of risks, benefits and adaptation measures in relation to climate change impacts at operational/local scales. However, a consistent multi-model analysis of energy sector's vulnerability using harmonized input is of utmost importance to obtain a more comprehensive understanding and to develop effective strategies to reduce the energy sector's vulnerability to climate change at the regional and global levels.

\section{Methods}

We conducted a literature search in in Scopus, Web of Science, Science Direct and Google Scholar. The search terms returned a total of more than 4,000 articles. After reviewing the broad range of articles based on their titles and abstracts, we narrowed our search criteria to select studies focusing only on the impacts of climate change on energy systems.

Literature selection. The literature filtering criteria was based broadly on representation of: (1) the near $(2,050)$, medium $(2,080)$ and/or far $(2,100)$ future scenarios; (2) clearly stated emission scenarios and/or warming levels and (3) national/regional and/or global analysis. Generic studies with no explicit mention of impact period, emission scenarios and/or warming levels were chiefly excluded from the review, while those with relevant statistics were included on 'Others' section of this review. Furthermore, micro-level and plant-based studies were not included in this review in favour of those with more national/regional and global coverages.

The search terms used for this are: 'climate impact energy', 'climate impact electricity', 'climate impact transmission', 'climate impact power generation', 'climate impact electricity generation', 'climate impact power production', 'climate impact power supply', 'climate impact renewable energy', 'climate impact solar energy', 'climate impact hydropower energy', 'climate impact wind energy', 'climate impact heating cooling energy', 'climate impact energy expenditure', 'climate impact energy cost', 'climate impact economy', 'climate impact energy consumption', 'climate impact energy supply', 'climate impact energy demand,' 'climate impact bioenergy', 'climate impact biomass energy', 'climate impact energy transport', 'climate impact energy transmission', 'climate impact energy grid', 'climate change energy price' and 'climate impact energy performance.' The papers included in this review are listed in Supplementary Table 1.

Regional aggregation. We classified the identified articles according to their focus into energy supply (that is, bioenergy, hydropower, solar, wind and thermal power sources), energy demand (impact on cooling and heating demand) or integrating systems including costs, and transport/transmission of energy (Fig. 2). Note that climate change impact on traditional primary extractive industries (for example, coal, oil and gas) were not included and no assessments at the regional or global scale in the academic literature was available in this topic, although they do exist in the industry.

Further, we classified the identified articles into aggregated global regions (see Supplementary Note I for the list of countries aggregated in each region). It is understandable that regional definitions and aggregations could present the risk of lumping opposing climate impact signals in different countries in similar regions (which could lead to a cancelling out of climate impacts). We applied an 11 global regions definition in this study to provide a reasonable overview of trends and potential climate change impacts on energy systems in global and larger world regions.

Analysis. After selecting and classifying the identified papers, we conducted a meta-analysis and generated the number of papers published per year and per region, including associated numbers of citations. Further, we went through each article to pick results of climate change impact on energy systems, in terms of percentage changes, and categorized these results per technology, per region, per warming level $\left(<2^{\circ} \mathrm{C}\right.$ or $\left.>2{ }^{\circ} \mathrm{C}\right)$ and per scenario years (rounded to 2050,2080 or 2100). In the classification of the scenario years, we applied 2050 for result scenarios of 2030-2070; 2080 for result scenarios of 2071-2085 and 2100 for result scenarios of $2086-2100$.

We generated Figs. 2-4 on the basis of the results gathered from this literature. Accordingly, Fig. 2 illustrates number of papers published per year or per category of energy systems. Figure 3 combines several data types, inducing the energy system categories, climate impacts in terms of percentage changes, regional versus global aggregations, warming levels with a threshold of $2{ }^{\circ} \mathrm{C}$ and scenario years. A box plot is used to illustrate these data types displaying a five-number statistical summary of the data set: minimum (end of line, left), first quartile (end of box, left), median (midline in the box), third quartile (right from midline in the box) and maximum (end of line, right). While dots are used to represent individual studies and boxes to represent interquartile ranges in the figure, dots outside the lines are statistical 'outliers'. Figure 4 was generated by averaging climate change impact percentage results of articles per region. The number of articles behind this averaging is presented in Supplementary Table 2.

\section{Data availability}

All data that support the findings of this study presented in the figures are provided in the Source Data section associated with this manuscript. Source data are provided with this paper.

Received: 13 August 2019; Accepted: 1 July 2020;

Published online: 3 August 2020 


\section{References}

1. Bruckner, T. et al. in Climate Change 2014: Mitigation of Climate Change (eds Edenhofer, O. et al.) (Cambridge Univ. Press, 2014).

2. Schaeffer, R. et al. Energy sector vulnerability to climate change: a review. Energy 38, 1-12 (2012).

3. Ebinger, J. \& Vergara, W. Climate Impacts on Energy Systems: Key Issues for Energy Sector Adaptation (The World Bank, 2011).

4. Crook, J. A., Jones, L. A., Forster, P. M. \& Crook, R. Climate change impacts on future photovoltaic and concentrated solar power energy output Energ. Environ, Sci. 4, 3101-3109 (2011).

5. Owusu, P. A. \& Asumadu-Sarkodie, S. A review of renewable energy sources, sustainability issues and climate change mitigation. Cogent. Eng. 3, 1167990 (2016).

6. Bartos, M. D. \& Chester, M. V. Impacts of climate change on electric power supply in the Western United States. Nat. Clim. Change 5, 748-752 (2015).

7. Karnauskas, K. B., Lundquist, J. K. \& Zhang, L. Southward shift of the global wind energy resource under high carbon dioxide emissions. Nar. Geosci. 11, 38-43 (2018).

8. Craig, M. T. et al. A review of the potential impacts of climate change on bulk power system planning and operations in the United States. Renew. Sust. Energ. Rev. 98, 255-267 (2018).

9. Van Vliet, M. T. et al. Vulnerability of US and European electricity supply to climate change. Nat. Clim. Change 2, 676 (2012).

10. Liu, L., Hejazi, M., Li, H., Forman, B. \& Zhang, X. Vulnerability of US thermoelectric power generation to climate change when incorporating state-level environmental regulations. Nat. Ener. 2, 17109 (2017).

11. Ciscar, J.-C. \& Dowling, P. Integrated assessment of climate impacts and adaptation in the energy sector. Energy Econ. 46, 531-538 (2014).

12. Ravestein, P., van der Schrier, G., Haarsma, R., Scheele, R. \& van den Broek, M. Vulnerability of European intermittent renewable energy supply to climate change and climate variability. Renew. Sust. Ener. Rev. 97, 497-508 (2018).

13. Perera, A., Nik, V. M., Chen, D., Scartezzini, J. L. \& Hong, T. Quantifying the impacts of climate change and extreme climate events on energy systems. Nat. Energy 5, 150-159 (2020)

14. IPCC Climate Change 2014: Synthesis Report (eds Core Writing Team, Pachauri, R. K. \& Meyer L. A.) (IPCC, 2014)

15. Isaac, M. \& van Vuuren, D. P. Modeling global residential sector energy demand for heating and air conditioning in the context of climate change. Energy Policy 37, 507-521 (2009).

16. IPCC Climate Change 2014: Impacts, Adaptation, and Vulnerability (eds Field, C. B. et al.) (Cambridge Univ. Press, 2014).

17. Cinner, J. E. et al. Building adaptive capacity to climate change in tropical coastal communities. Nat. Clim. Change 8, 177-123 (2018).

18. Lumbroso, D., Woolhouse, G. \& Jones, L. A review of the consideration of climate change in the planning of hydropower schemes in sub-Saharan Africa. Clim. Change 133, 621-633 (2015).

19. Kabir, E., Kumar, P., Kumar, S., Adelodun, A. A. \& Kim, K.-H. Solar energy: potential and future prospects. Renew. Sust. Energ. Rev. 82, 894-900 (2018).

20. Pryor, S. \& Barthelmie, R. Climate change impacts on wind energy: a review. Renew. Sust. Energ. Rev. 14, 430-437 (2010).

21. Berndes, G., Hoogwijk, M. \& Van den Broek, R. The contribution of biomass in the future global energy supply: a review of 17 studies. Biomass Bioenerg. 25, 1-28 (2003).

22. Li, D. H., Yang, L. \& Lam, J. C. Impact of climate change on energy use in the built environment in different climate zones-a review. Energy 42, 103-112 (2012).

23. Auffhammer, M. \& Mansur, E. T. Measuring climatic impacts on energy consumption: a review of the empirical literature. Energy Econ. 46, 522-530 (2014).

24. Mideksa, T. K. \& Kallbekken, S. The impact of climate change on the electricity market: a review. Energy Policy 38, 3579-3585 (2010).

25. Chandramowli, S. N. \& Felder, F. A. Impact of climate change on electricity systems and markets-a review of models and forecasts. Sust. Energ. Technol. Assess. 5, 62-74 (2014).

26. Mikellidou, C. V., Shakou, L. M., Boustras, G. \& Dimopoulos, C. Energy critical infrastructures at risk from climate change: a state of the art review. Safety Science 110, https://doi.org/10.1016/j.ssci.2017.12.022 (2017).

27. Stanton, M. C. B., Dessai, S. \& Paavola, J. A systematic review of the impacts of climate variability and change on electricity systems in Europe. Energy 109, 1148-1159 (2016).

28. Cronin, J., Anandarajah, G. \& Dessens, O. Climate change impacts on the energy system: a review of trends and gaps. Clim. Change 151, 79-93 (2018).

29. Barnett, T. P., Adam, J. C. \& Lettenmaier, D. P. Potential impacts of a warming climate on water availability in snow-dominated regions. Nature 438, 303 (2005).

30. Chilkoti, V., Bolisetti, T. \& Balachandar, R. Climate change impact assessment on hydropower generation using multi-model climate ensemble. Renew. Energ. 109, 510-517 (2017).
31. Fan, J.-L. Impacts of climate change on hydropower generation in China. Comput. Simulat. 167, 4-18 (2018)

32. Teotónio, C., Fortes, P., Roebeling, P., Rodriguez, M. \& Robaina-Alves, M. Assessing the impacts of climate change on hydropower generation and the power sector in Portugal: a partial equilibrium approach. Renew. Sust. Energ. Rev. 74, 788-799 (2017).

33. Hamududu, B. \& Killingtveit, A. Assessing climate change impacts on global hydropower. Energies 5, 305-322 (2012).

34. Van Vliet, M. T., Wiberg, D., Leduc, S. \& Riahi, K. Power-generation system vulnerability and adaptation to changes in climate and water resources. Nat. Clim. Change 6, 375-380 (2016).

35. Van Vliet, M. et al. Multi-model assessment of global hydropower and cooling water discharge potential under climate change. Global Environ. Change 40, 156-170 (2016).

36. Turner, S. W., Ng, J. Y. \& Galelli, S. Examining global electricity supply vulnerability to climate change using a high-fidelity hydropower dam model. Sci. Total Environ. 590, 663-675 (2017).

37. Zhou, Y. et al. A comprehensive view of global potential for hydro-generated electricity. Energ. Environ. Sci. 8, 2622-2633 (2015).

38. Raje, D. \& Mujumdar, P. Reservoir performance under uncertainty in hydrologic impacts of climate change. Adv. Water Resour. 33 312-326 (2010).

39. Gaudard, L., Gilli, M. \& Romerio, F. Climate change impacts on hydropower management. Water Resource. Manag. 27, 5143-5156 (2013).

40. Mohor, G. S., Rodriguez, D. A., Tomasella, J. \& Júnior, J. L. S. Exploratory analyses for the assessment of climate change impacts on the energy production in an Amazon run-of-river hydropower plant. J. Hydrol. Reg. Studies 4, 41-59 (2015).

41. Fant, C., Schlosser, C. A. \& Strzepek, K. The impact of climate change on wind and solar resources in southern Africa. Appl. Energy 161, 556-564 (2016).

42. Wachsmuth, J. et al. How will renewable power generation be affected by climate change? The case of a Metropolitan Region in Northwest Germany. Energy 58, 192-201 (2013).

43. Jerez, S. et al. The impact of climate change on photovoltaic power generation in Europe. Nat. Commun. 6, 10014 (2015)

44. Bartók, B. et al. Projected changes in surface solar radiation in CMIP5 global climate models and in EURO-CORDEX regional climate models for Europe. Climate Dynam. 49, 2665-2683 (2017).

45. Davy, R., Gnatiuk, N., Pettersson, L. \& Bobylev, L. Climate change impacts on wind energy potential in the European domain with a focus on the Black Sea. Renew. Sust. Energ. Rev. 81, 1652-1659 (2017).

46. Carvalho, D., Rocha, A., Gómez-Gesteira, M. \& Santos, C. S. Potential impacts of climate change on European wind energy resource under the CMIP5 future climate projections. Renew. Energ. 101, 29-40 (2017).

47. Hueging, H., Haas, R., Born, K., Jacob, D. \& Pinto, J. G. Regional changes in wind energy potential over Europe using regional climate model ensemble projections. J. Appl. Meteorol. Climatol. 52, 903-917 (2013).

48. Tobin, I. et al. Vulnerabilities and resilience of European power generation to $1.5^{\circ} \mathrm{C}, 2^{\circ} \mathrm{C}$ and $3{ }^{\circ} \mathrm{C}$ warming. Environ. Res. Lett. 13, 044024 (2018).

49. Vautard, R. et al. Regional climate model simulations indicate limited climatic impacts by operational and planned European wind farms. Nat. Commun. 5, 3196 (2014).

50. Jerez, S. et al. Future changes, or lack thereof, in the temporal variability of the combined wind-plus-solar power production in Europe. Renew. Energy 139, 251-260 (2019)

51. De Lucena, A. F. P., Szklo, A. S., Schaeffer, R. \& Dutra, R. M. The vulnerability of wind power to climate change in Brazil. Renew. Energy 35, 904-912 (2010).

52. Pereira, E. B., Martins, F. R., Pes, M. P., da Cruz Segundo, E. I. \& Lyra, Ad. A. The impacts of global climate changes on the wind power density in Brazil. Renew. Energy 49, 107-110 (2013).

53. Breslow, P. B. \& Sailor, D. J. Vulnerability of wind power resources to climate change in the continental United States. Renew. Energy 27, 585-598 (2002).

54. Sailor, D. J., Smith, M. \& Hart, M. Climate change implications for wind power resources in the Northwest United States. Renew. Energy 33, 2393-2406 (2008).

55. De Jong, P. et al. Estimating the impact of climate change on wind and solar energy in Brazil using a South American regional climate model. Renew. Energy 141, 390-401 (2019).

56. Tuck, G., Glendining, M. J., Smith, P., House, J. I. \& Wattenbach, M. The potential distribution of bioenergy crops in Europe under present and future climate. Biomass Bioenerg. 30, 183-197 (2006).

57. Bellarby, J., Wattenbach, M., Tuck, G., Glendining, M. J. \& Smith, P. The potential distribution of bioenergy crops in the UK under present and future climate. Biomass Bioenerg. 34, 1935-1945 (2010).

58. Harvey, M. \& Pilgrim, S. The new competition for land: food, energy, and climate change. Food Policy 36, S40-S51 (2011). 
59. Kyle, P., Müller, C., Calvin, K. \& Thomson, A. Meeting the radiative forcing targets of the representative concentration pathways in a world with agricultural climate impacts. Earth's Future 2, 83-98 (2014).

60. Miara, A., Vörösmarty, C. J., Stewart, R. J., Wollheim, W. M. \& Rosenzweig, B. Riverine ecosystem services and the thermoelectric sector: strategic issues facing the Northeastern United States. Environ. Res. Lett. 8 , 025017 (2013).

61. Miara, A. et al. Climate and water resource change impacts and adaptation potential for US power supply. Nat. Clim. Change 7, 793-798 (2017).

62. Miara, A. et al. Climate-water adaptation for future US electricity infrastructure. Environ. Sci. Technol. 53, 14029-14040 (2019).

63. Byers, E., Hall, J., Amezaga, J., O’Donnell, G. \& Leathard, A. Water and climate risks to power generation with carbon capture and storage. Environ. Res. Lett. 11, 024011 (2016).

64. Angeles, M. E., González, J. E. \& Ramírez, N. Impacts of climate change on building energy demands in the intra-Americas region. Theoret. Appl. Climatol 133, 59-72 (2018)

65. Fan, J.-L., Hu, J.-W. \& Zhang, X. Impacts of climate change on electricity demand in China: an empirical estimation based on panel data. Energy 170, 880-888 (2019).

66. Taseska, V., Markovska, N. \& Callaway, J. M. Evaluation of climate change impacts on energy demand. Energy 48, 88-95 (2012).

67. Allen, M. R., Fernandez, S. J., Fu, J. S. \& Olama, M. M. Impacts of climate change on sub-regional electricity demand and distribution in the southern United States. Nat. Energy 1, 16103 (2016).

68. Zhou, Y. et al. Modeling the effect of climate change on US state-level buildings energy demands in an integrated assessment framework. Appl. Energy 113, 1077-1088 (2014).

69. Hadley, S. W., Erickson Iii, D. J., Hernandez, J. L., Broniak, C. T. \& Blasing, T. J. Responses of energy use to climate change: a climate modeling study. Geophys. Res. Lett. 33, https://doi.org/10.1029/2006GL026652 (2006).

70. Eom, J., Clarke, L., Kim, S. H., Kyle, P. \& Patel, P. China’s building energy demand: long-term implications from a detailed assessment. Energy 46, 405-419 (2012).

71. McFarland, J. et al. Impacts of rising air temperatures and emissions mitigation on electricity demand and supply in the United States: a multi-model comparison. Clim. Change 131, 111-125 (2015).

72. Clarke, L. et al. Effects of long-term climate change on global building energy expenditures. Energy Econ. 72, 667-677 (2018).

73. Labriet, M. et al. Worldwide impacts of climate change on energy for heating and cooling. Mit. Adapt. Strat. Global Change 20, 1111-1136 (2015)

74. Van Ruijven, B. J., De Cian, E. \& Wing, I. S. Amplification of future energy demand growth due to climate change. Nat. Commun. 10, 2762 (2019).

75. De Cian, E. \& Wing, I. S. Global energy consumption in a warming climate. Environ. Res. Econ. 72, 365-410 (2019).

76. Auffhammer, M., Baylis, P. \& Hausman, C. H. Climate change is projected to have severe impacts on the frequency and intensity of peak electricity demand across the United States. Proc. Natl Acad. Sci. USA 114, 1886-1891 (2017).

77. De Cian, E., Lanzi, E. \& Roson, R. Seasonal temperature variations and energy demand. Clim. Change 116, 805-825 (2013).

78. Invidiata, A. \& Ghisi, E. Impact of climate change on heating and cooling energy demand in houses in Brazil. Energ. Buildings 130, 20-32 (2016).

79. Wang, H. \& Chen, Q. Impact of climate change heating and cooling energy use in buildings in the United States. Energ. Buildings 82, 428-436 (2014).

80. Hamlet, A. F., Lee, S.-Y., Mickelson, K. E. \& Elsner, M. M. Effects of projected climate change on energy supply and demand in the Pacific Northwest and Washington State. Clim. Change 102, 103-128 (2010).

81. Davis, L. W. \& Gertler, P. J. Contribution of air conditioning adoption to future energy use under global warming. Proc. Natl Acad. Sci. USA 112, 5962-5967 (2015).

82. Park, C. et al. Avoided economic impacts of energy demand changes by 1.5 and $2{ }^{\circ} \mathrm{C}$ climate stabilization. Environ. Res. Lett. 13, 045010 (2018).

83. Waite, M. et al. Global trends in urban electricity demands for cooling and heating. Energy 127, 786-802 (2017).

84. Morakinyo, T. E. et al. Estimates of the impact of extreme heat events on cooling energy demand in Hong Kong. Renew. Energy 142, $73-84$ (2019).

85. Moazami, A., Nik, V. M., Carlucci, S. \& Geving, S. Impacts of future weather data typology on building energy performance-Investigating long-term patterns of climate change and extreme weather conditions. Appl. Energy 238, 696-720 (2019).

86. Dirks, J. A. et al. Impacts of climate change on energy consumption and peak demand in buildings: a detailed regional approach. Energy 79 20-32 (2015)

87. D'Oca, S., Hong, T. \& Langevin, J. The human dimensions of energy use in buildings: a review. Renew. Sust. Energy Rev. 81, 731-742 (2018).

88. Poortinga, W., Steg, L. \& Vlek, C. Values, environmental concern, and environmental behavior: a study into household energy use. Environ. Behav. 36, 70-93 (2004)
89. De Cian, E., Pavanello, F., Randazzo, T., Mistry, M. N. \& Davide, M. Households' adaptation in a warming climate. Air conditioning and thermal insulation choices. Environ. Sci. Policy 100, 136-157 (2019).

90. Castleton, H. F., Stovin, V., Beck, S. B. \& Davison, J. B. Green roofs building energy savings and the potential for retrofit. Energy Buildings 42, 1582-1591 (2010).

91. Jones, P., Lannon, S. \& Patterson, J. Retrofitting existing housing: how far, how much? Building Res. Info. 41, 532-550 (2013).

92. Da Silva Soito, J. L. \& Freitas, M. A. V. J. R. Amazon and the expansion of hydropower in Brazil: vulnerability, impacts and possibilities for adaptation to global climate change. Renew. Sust. Energy Rev. 15, 3165-3177 (2011).

93. Cohen, S. M., Macknick, J., Averyt, K. \& Meldrum, J. Modeling Climate-Water Impacts on Electricity Sector Capacity Expansion (National Renewable Energy Laboratory, 2014).

94. Mima, S. \& Criqui, P. The costs of climate change for the European energy system, an assessment with the POLES model. Environ. Model. Ass. 20 303-319 (2015).

95. Ackerman, F. \& Stanton, E. A. The Cost of Climate Change: What We'll Pay if Global Warming Continues Unchecked (Natural Resources Defence Council, 2008).

96. Turner, S. W., Hejazi, M., Kim, S. H., Clarke, L. \& Edmonds, J. Climate impacts on hydropower and consequences for global electricity supply investment needs. Energy 141, 2081-2090 (2017).

97. Van der Linden, P. \& Mitchell, J. (eds) ENSEMBLES: Climate Change and its Impacts-Summary of Research and Results from the ENSEMBLES Project (European Environment Agency, 2009).

98. Rübbelke, D. \& Vögele, S. Impacts of climate change on European critical infrastructures: the case of the power sector. Environ. Sci. Policy 14, 53-63 (2011).

99. Pryor, S. \& Barthelmie, R. Assessing the vulnerability of wind energy to climate change and extreme events. Clim. Change 121, 79-91 (2013).

100. Miller, N. L., Hayhoe, K., Jin, J. \& Auffhammer, M. Climate, extreme heat, and electricity demand in California. J. Appl. Meteorol. Climatol. 47, 1834-1844 (2008).

101. Forzieri, G. et al. Escalating impacts of climate extremes on critical infrastructures in Europe. Global Environ. Change 48, 97-107 (2018).

102. Bartos, M. et al. Impacts of rising air temperatures on electric transmission ampacity and peak electricity load in the United States. Environ. Res. Lett. 11, 114008 (2016).

103. Panteli, M. \& Mancarella, P. Influence of extreme weather and climate change on the resilience of power systems: Impacts and possible mitigation strategies. Electric Power Syst. Res. 127, 259-270 (2015).

104. Dowling, P. The impact of climate change on the European energy system. Energy Policy 60, 406-417 (2013).

105. Haddeland, I. et al. Multimodel estimate of the global terrestrial water balance: setup and first results. J. Hydrometeorol. 12, 869-884 (2011).

106. Schewe, J. et al. Multimodel assessment of water scarcity under climate change. Proc. Natl Acad. Sci. USA 111, 3245-3250 (2014).

107. Rosenzweig, C. et al. The agricultural model intercomparison and improvement project (AgMIP): protocols and pilot studies. Agri. Forest Meteorol. 170, 166-182 (2013).

108. van Vuuren, D. P. \& Carter, T. R. Climate and socio-economic scenarios for climate change research and assessment: reconciling the new with the old. Clim. Change 122, 415-429 (2014).

109. Van Vuuren, D. P. et al. A new scenario framework for climate change research: scenario matrix architecture. Clim. Change 122, 373-386 (2014).

110. O’Neill, B. C. et al. A new scenario framework for climate change research: the concept of shared socioeconomic pathways. Clim. Change 122, 387-400 (2014).

111. Wiedenhofer, D., Lenzen, M. \& Steinberger, J. K. Energy requirements of consumption: urban form, climatic and socio-economic factors, rebounds and their policy implications. Energy Policy 63, 696-707 (2013).

112. Frieler, K. et al. Assessing the impacts of $1.5 \mathrm{C}$ global warming-simulation protocol of the Inter-Sectoral Impact Model Intercomparison Project (ISIMIP2b). Geosci. Model Dev. 10, 4321-4345 (2017).

\section{Acknowledgements}

We wish to thank the JPI Climate initiative and participating grant institutes for funding the ISIpedia project. We also thank J. Burrough for professional advice on the English of a near-final draft. E.d.C. has received funding from the European Research Council (ERC) under the European Union's Horizon 2020 research and innovation programme under grant agreement no. 756194 (ENERGYA). J.G. is supported by a research grant from Science Foundation Ireland (SFI) and the National Natural Science Foundation of China (NSFC) under the SFI-NSFC Partnership Programme, grant no. 17/NSFC/5181. D.P.v.V., R.S. and D.E.H.J.G. are supported by the Horizon 2020 NAVIGATE project, and D.P.v.V., R.S. and D.E.H.J.G. also acknowledge support from the COMMIT and Horizon 2020 ENGAGE project. F.P. acknowledges support through the project ENGAGE funded in the framework of the Leibniz Competition (SAW-2016-PIK-1), as well as through the project CHIPS, part of AXIS, an ERA-NET initiated by JPI Climate, and funded by 
FORMAS (SE), DLR/BMBF (DE, grant no. 01LS19XXY), AEI (ES) and ANR (FR) with cofunding by the European Union (grant no. 776608). R.S. acknowledges the financial support from the National Council for Scientific and Technological Development (CNPq), from the National Institute of Science and Technology for Climate Change Phase 2 under CNPq grant no. 465501/2014-1 and the National Coordination for High Level Education and Training (CAPES) grant no. 88887.136402/2017-00, all from Brazil. A.M. acknowledges support from the US Department of Energy, Office of Science's Integrated Multisector Multiscale Modelling project and National Science Foundation's Water Sustainability and Climate grant no. 1360445. This work was authored in part by the National Renewable Energy Laboratory (A.M.), operated by Alliance for Sustainable Energy, LLC, for the US Department of Energy (DOE) under Contract No. DE-AC36-08GO28308. S.F. is supported by the Environment Research and Technology Development Fund (2-1908 and 2-2002) provided by the Environmental Restoration and Conservation Agency, Japan. C.P. is supported by Korea Environment Industry \& Technology Institute (KEITI) through Climate Change R\&D Programme, funded by the Korea Ministry of Environment (MOE) (2018001310003).

\section{Author contributions}

S.G.Y. and D.P.v.V. codesigned the study. S.G.Y. collected and analysed data, and cowrote the initial draft manuscript with D.P.v.V. S.G.Y., D.P.v.V. and M.T.H.v.V. performed sectoral analysis of energy systems. S.G.Y., D.P.v.V., M.T.H.v.V., D.E.H.J.G., F.L., A.M., C.P., E.B., E.d.C., F.P., G.I., I.M., J.G., M.H., O.D., P.R., R.P., R.S., S.F., S.D., S.M., S.R.S.d.S., V.C. and R.V. contributed to the review of sectoral and regional climate impacts.

\section{Competing interests}

The authors declare no competing interests.

\section{Additional information}

Supplementary information is available for this paper at https://doi.org/10.1038/ s41560-020-0664-z.

Correspondence and requests for materials should be addressed to S.G.Y.

Reprints and permissions information is available at www.nature.com/reprints.

Publisher's note Springer Nature remains neutral with regard to jurisdictional claims in published maps and institutional affiliations.

(c) The Author(s), under exclusive licence to Springer Nature Limited 2020 